\title{
RESEARCH
}

Open Access

\section{Correlation of MRI and arthroscopic findings with clinical outcome in temporomandibular joint disorders: a retrospective cohort study}

Kobbe Vervaeke ${ }^{1,2}$, Pieter-Jan Verhelst ${ }^{1,2}$, Kaan Orhan ${ }^{2,3}$, Bodil Lund ${ }^{4,5,6}$, Daniel Benchimol ${ }^{6}$, Fréderic Van der Cruyssen ${ }^{1,2}$, Antoon De Laat ${ }^{1,7,8}$, Reinhilde Jacobs ${ }^{1,2,6^{*}}$ (D) and Constantinus Politis ${ }^{1,2}$

\begin{abstract}
Background: Arthroscopy is a minimally invasive diagnostic tool and treatment strategy in patients suffering from temporomandibular disorders (TMD) when conservative treatment fails. This study aimed to find specific variables on pre-operative MRI or during arthroscopy that could predict success of arthroscopic lysis and lavage.

Methods: This retrospective analysis compared pre-operative maximum interincisal opening (MIO), pain and main complaint (pain, limited MIO or joint sounds) with results at short-term and medium-term follow-up (ST and MT respectively). Different variables scored on MRI or arthroscopy were used to make a stepwise regression model, subsequently a combined analysis was conducted using variables from both MRI and arthroscopy.
\end{abstract}

Results: A total of 47 patients (50 joints) met the inclusion criteria. The main complaint improved by 62 and $53 \%$ at ST and MT respectively. The absolute or probable absence of a crumpled disc scored on MRI predicted success at ST and MT ( $p=0.0112$ and $p=0.0054)$, and remained significant at MT in the combined analysis $(p=0.0078)$. Arthroscopic findings of degenerative joint disease predicted success at ST ( $p=0.0178$ ), absolute or probable absence of discal reduction scored during arthroscopy significantly predicted success in the combined analysis at ST $(p=0.0474)$.

Conclusion: To improve selection criteria for patients undergoing an arthroscopic lysis and lavage of the TMJ, future research might focus on variables visualized on MRI. Although more research is needed, disc shape and in particular the absolute or probable absence of a crumpled disc might be used as predictive variable for success.

Keywords: Arthroscopy, Crumpled disc, Degenerative joint disease, MRI, Temporomandibular disorders, Temporomandibular joint

\footnotetext{
* Correspondence: reinhilde.jacobs@ki.se

'Department of Oral and Maxillofacial Surgery, University Hospitals Leuven, Campus Sint-Rafaël, Kapucijnenvoer 33, BE-3000 Leuven, Belgium

${ }^{2} \mathrm{OMFS}$ IMPATH Research Group, Department of Imaging and Pathology, Faculty of Medicine, KU Leuven, Leuven, Belgium

Full list of author information is available at the end of the article
}

(c) The Author(s). 2022 Open Access This article is licensed under a Creative Commons Attribution 4.0 International License, which permits use, sharing, adaptation, distribution and reproduction in any medium or format, as long as you give appropriate credit to the original author(s) and the source, provide a link to the Creative Commons licence, and indicate if changes were made. The images or other third party material in this article are included in the article's Creative Commons licence, unless indicated otherwise in a credit line to the material. If material is not included in the article's Creative Commons licence and your intended use is not permitted by statutory regulation or exceeds the permitted use, you will need to obtain permission directly from the copyright holder. To view a copy of this licence, visit http://creativecommons.org/licenses/by/4.0/ The Creative Commons Public Domain Dedication waiver (http://creativecommons.org/publicdomain/zero/1.0/) applies to the data made available in this article, unless otherwise stated in a credit line to the data. 


\section{Introduction}

Temporomandibular disorders (TMD) are a heterogeneous group of conditions involving the temporomandibular joint (TMJ) and associated structures. Patients suffering from TMD most often present with pain, limited mouth opening and joint sounds [1, 2]. The prevalence of TMD is highest in young and middle-aged women (20-50 years), female-to-male ratio ranges from 3:1 to 9:1. Women also seek treatment three times more often than men [2-4]. Approximately 85 to $90 \%$ of patients benefit from non-invasive treatment such as reduction of joint loading by education, occlusal splints, NSAIDs or other pharmacological strategies. Generally, non-surgical treatment needs to be continued for at least three to six months before more invasive therapies such as arthrocentesis or arthroscopy are considered $[1,2]$.

Arthroscopy of the TMJ was first described by Onishi in 1975 [5]. In 1986, Sanders described the arthroscopic lysis and lavage for the treatment of internal derangement with persistent closed lock. The term lysis indicates that adhesions in the superior compartment of the joint are detached. At the same time, intra-articular inflammatory substances are washed out by the lavage [6]. Since then this technique has been used in the management of internal derangements and degenerative joint disease (DJD). Success rates of arthroscopic lysis and lavage in short-term and long-term follow-up studies are on average between 54 and $80 \%$ when it comes to pain reduction and increase in mouth opening [7-12].

In therapy-resistant cases, additional imaging of the TMJ is often required. MRI is the gold standard to evaluate the soft tissue components of the TMJ and is effective for the detection of early signs of TMJ dysfunction like joint effusion, changes in disc shape and position, and thickening of the anterior or posterior band [13]. While MRI is also reliable for the detection of internal derangement, especially for anterior disc displacement with reduction (ADDwR), the diagnostic accuracy for evaluating the presence of intra-articular adhesions is rather poor [14-16].Joint effusion seen on MRI has been examined as a potential predictor for successful arthroscopy in the past but was not associated with better postoperative outcome [17].

Previous research focused mainly on clinical parameters for predicting success of arthroscopy.

Psychiatric disorders, concurrent use of benzodiazepines, high self-graded global pain, bilateral muscle tenderness at palpation and small MIO are all correlated with a negative outcome $[7,18,19]$. A recent retrospective study of Muñoz-Guerra et al. also showed no significant correlation between age and postoperative improvement referred to pain or MIO [11].

Because MRI and arthroscopy are commonly done in the refractory TMD patient group, it would be beneficial to identify which diagnostic findings are associated with a higher success rate of the lysis and lavage effect of arthroscopy. In a previous article we already assessed the correlation between MRI and arthroscopic findings was. We found that the agreement between MRI and arthroscopy was poor, which means that when blinded to clinical information MRI and arthroscopic observations can lead to different conclusions. It is therefore important to combine both examinations with clinical information to arrive to a final diagnosis [20]. In this article we focus more on the clinical side. The aim of this study therefore is to identify predictive variables to help physicians predict which patients might benefit the most from an arthroscopy.

\section{Material and methods Study design and patients}

All patients who had a diagnostic arthroscopy of the TMJ at the Department of Oral and Maxillofacial Surgery at the University Hospital of Leuven, Belgium, during a five-year period (01-10-2013 until 31-10-2018) were reviewed. A total of 47 patients (50 joints) met the inclusion criteria and were included in this single-centre, retrospective observational study. Ethical approval was given by the Research Ethics Committee UZ/KU Leuven (MP 012487).

Patients of all ages and genders were included if they met following criteria: 1) An MRI of the TMJ was taken no more than six months before the arthroscopy and MRI imaging was available through exportable DICOM data, 2) A video recording of the arthroscopy was available, 3) Preoperative clinical examination parameters were available. Patients were excluded if they did not meet the criteria listed above or if they: 1) Did not have a follow-up appointment in the six weeks after arthroscopy, 2) If a concomitant TMJ surgery was done during arthroscopy.

\section{Clinical variables}

Patient files were searched for clinical variables prior to surgery, at the short-term follow-up (ST) less than six weeks after surgery and at the first medium-term followup (MT) more than six weeks after surgery. Preoperative maximum inter-incisal opening $(\mathrm{MIO})(\mathrm{mm})$, presence of pain in the TMJ (Yes/No) and presence of TMJ sounds (Yes/No) were extracted from the patient files. The symptom that interfered most with their daily living activities was categorized as the patient's main complaint. MIO and the presence of pain and sounds were scored again at both short-term and medium-term follow-up. A limited mouth opening, defined as MIO of $35 \mathrm{~mm}$ or less (yes/no) was registered as well as a general improvement in pain (yes/no) and improvement in main complaint (yes/no). Each joint received one or 
Table 1 Scoring system for MRI and arthroscopy

\begin{tabular}{|c|c|c|}
\hline & MRI & Arthroscopy \\
\hline Discal displacement & Likert & Likert \\
\hline Anterior & Likert & Likert \\
\hline - Posterior & Likert & Likert \\
\hline - Partial & Likert & Likert \\
\hline - Reduction & Likert & Likert \\
\hline Discal deformation & Likert & Likert \\
\hline - Crumpled disc & Likert & Likert \\
\hline - Rounded disc & Likert & Likert \\
\hline - Flat disc & Likert & Likert \\
\hline - Disc perforations & Likert & Likert \\
\hline Adhesions & Likert & Likert \\
\hline Joint effusion & Likert & - \\
\hline Lateral pterygoid muscle anomalies & Likert & - \\
\hline Pterygoid shadow anomaly & - & Likert \\
\hline Retrodiscal deformation & Likert & Likert \\
\hline Glenoid fossa deformation & Likert & Likert \\
\hline - Chondromalacia grade & - & Grading \\
\hline Articular eminence deformation & Likert & Likert \\
\hline - Chondromalacia grade & - & Grading \\
\hline Condylar deformation & Likert & - \\
\hline Overall synovitis & - & Likert \\
\hline \multicolumn{3}{|l|}{ Haemorrhagic infiltrations } \\
\hline - Anterior band of the disc & - & Grading \\
\hline - Posterior band of the disc & - & Grading \\
\hline - Retrodiscal synovium & - & Grading \\
\hline - Anterior recess & - & Grading \\
\hline - Fossa & - & Grading \\
\hline - Articular eminence & - & Grading \\
\hline - Medial synovium & - & Grading \\
\hline
\end{tabular}

Likert scale 1 to 5 :

1. Absolutely not

2. Probably not

3. Uncertain

4. Probably yes

5. Absolutely yes

Synovitis Grading

0 . Normal, with whitish synovial tissue and wire capillaries

1. Light hypervascularity, with larger capillaries

2. Moderate hypervascularity, with the presence of petechiae

3. Severe hypervascularity, with the presence of broad areas

of petechiae/ecchymosis

Chondromalacia Grading

0 . Normal, completely smooth, smooth white surface with striations on the surface

1. Surface degeneration

2. Intermediate degeneration, with fibrocartilage with bubbles, but without

bone exposure

3. Advanced degeneration, with evident bone exposure throughout the joint

If a variable is not assessed on MRI or arthroscopy, it is indicated with '-'

more diagnostic labels based upon clinical findings prior to surgery; Anterior Disc Displacement without Reduction (ADDwoR), Anterior Disc Displacement with
Reduction (ADDwR), Degenerative Joint Disease (DJD), Inflammatory Arthritis (IA), Fibrous Ankylosis and 'Others'.

\section{MRI and arthroscopy}

A scoring system was developed to evaluate the different structures of the TMJ on MRI and arthroscopic images in a reproducible and standardized manner (Table 1). All MRI and arthroscopic images were pseudonymised and evaluated by one oral and maxillofacial radiologist and surgeon respectively. A tentative diagnosis was made based upon these findings. These variables were then correlated with clinical parameters to check for findings that could predict success of arthroscopy.

All arthroscopic procedures were conducted by the same experienced maxillofacial surgeon using a $1.9 \mathrm{~mm}$ and $30^{\circ}$ arthroscope with two 2.7 outer protective cannulas as described by McCain and colleagues [21]. An arthroscopy in our centre is performed in following patients: persistent pain in the TMJ that is arthrogenous of origin AND the pain did not respond to at least three months of conservative treatment AND the pain is of such nature that it interferes with the patient's daily life. The decision to inject intra-articular corticoids (Diprophos $^{\circ}$, betamethasone) was made based upon the perioperative arthroscopic findings of the degree of inflammation of the synovium. Hyaluronic acid was only injected if there was evidence of severe degenerative joint disease.

\section{Statistical analysis}

Data were analysed using IBM SPSS Statistics for Windows, version 26. Fisher's exact test was used for bivariate data and the Student t-test for mean values. A stepwise regression model (bidirectional elimination) was used for making a model selection. First, a separate model was made for MRI and arthroscopy, subsequently a combined analysis was conducted. A $P$-value of less than 0.05 was set to be significant.

\section{Results}

\section{Preoperative demographic data}

A total of 47 patients (50 joints) met the inclusion criteria (Table 2). Two patients underwent an arthroscopy of both TMJ's on the same day. One patient presented with similar complaints in the other TMJ after a first arthroscopy. She had a second arthroscopy on the other side 21 months after the first one. All patients had a post-operative appointment within six weeks after surgery with an average of 1.5 weeks (ST) $\quad(\mathrm{SD}=0,76)$, while 36 patients also had a medium-term follow-up appointment, on average 5.4 months after arthroscopy (MT) $(\mathrm{SD}=1,74)$. 
Table 2 Patients characteristics

\begin{tabular}{|c|c|c|c|}
\hline \multirow[b]{2}{*}{ Patients } & & \multirow{2}{*}{$\begin{array}{l}n \\
47\end{array}$} & \multirow{2}{*}{$\begin{array}{l}\% \\
100 \%\end{array}$} \\
\hline & & & \\
\hline & Male & 5 & $11 \%$ \\
\hline & Female & 42 & $89 \%$ \\
\hline & Age (years) & 41 (mean) & $16(\mathrm{std})$ \\
\hline & Time First Consult-Arthro (months) & 18.9 (mean) & 34,5 (std) \\
\hline & Time MRI-Arthro (days) & 70,82 (mean) & $43,97(s t d)$ \\
\hline \multirow[t]{3}{*}{ Intra-articular injection } & Corticosteroids & 44 & $88 \%$ \\
\hline & Hyaluronic acid & 4 & $8 \%$ \\
\hline & None & 2 & $4 \%$ \\
\hline \multirow[t]{3}{*}{ Main complaint } & Pain & 42 & $89 \%$ \\
\hline & Limited maximum interincisal opening & 4 & $9 \%$ \\
\hline & Sounds & 1 & $2 \%$ \\
\hline \multirow[t]{6}{*}{ Diagnostic labels } & Anterior disc displacement without reduction & 20 & $40 \%$ \\
\hline & Anterior disc displacement with reduction & 3 & $6 \%$ \\
\hline & Degenerative joint disease & 23 & $46 \%$ \\
\hline & Inflammatory arthritis & 28 & $56 \%$ \\
\hline & Fibrous ankylosis & 5 & $10 \%$ \\
\hline & 'Other' & 2 & $4 \%$ \\
\hline
\end{tabular}

Age stands for the age at the time of arthroscopy. Time First Consult-Arthro is the time in months between the first consultation at our department and the diagnostic arthroscopy. Time MRI-Arthro is the time between the MRI scan and the arthroscopy. Limited MIO: a Maximum Interincisal Opening of $\leq 35$ mm

\section{Surgical outcome}

Average MIO did not differ significantly between the pre-operative consultation, the short-term and the medium-term follow-up (Table 3). Overall subjective improvement in main complaint was observed in $62 \%$ of patients at the ST and in 53\% at the MT. There was no significant difference in improvement in main complaint between men and women $(p=0.6348)$ at the short-term nor at the medium-term follow-up $(p=1)$.

\section{Stepwise regression model}

\section{Separate analyses}

In the analysis of the MRI, the absolute or probable absence of a crumpled disc (Fig. 1) was a significant predictor for improvement of the main complaint at short-term and medium-term follow-up ( $p=0.0112$ and $p=0.0054$ ) (Table 4$)$. In the patient group with pain as main complaint, the absolute absence of any sign of articular eminence deformation was the only variable significantly correlated with improvement of pain in ST and $\operatorname{MT}(p=0.0052$ and $p=0.0325)$. In the separate analysis for variables scored on arthroscopic images, only DJD significantly correlated with ST improvement of the main complaint $(p=0.0178)$.

\section{Combined analysis}

The absolute or probable absence of discal reduction observed on arthroscopic images correlated significantly with improvement of the main complaint $(p=0.0474)$, although in the short-term only. At the medium-term follow-up, the absolute or probable absence of a crumpled disc scored on MRI $(p=0.0078)$, remained a significant predictor for improvement of main complaint. Unfortunately, there was too little data to make any

Table 3 Surgical outcome

\begin{tabular}{|c|c|c|c|}
\hline & Pre-operative & Short-term follow-up & Medium-term follow-up \\
\hline Average MIO (mm) & $33.17 \mathrm{~mm}(\mathrm{SD}=9.97)$ & $33.02 \mathrm{~mm}(\mathrm{SD}=8.59)$ & 34.75 mm (SD = 7.34) \\
\hline Limited MIO (\%) & $66 \%(31 / 47)$ & $62 \%(29 / 47)$ & $56 \%(20 / 36)$ \\
\hline Pain (\%) & $100 \%(47 / 47)$ & $60 \%(28 / 47)$ & $67 \%(24 / 36)$ \\
\hline Objective improvement in $\mathrm{MIO}$ & & $32 \%(15 / 47)$ & $29 \%(10 / 36)$ \\
\hline Subjective improvement in MC & & $62 \%(29 / 47)$ & $53 \%(19 / 36)$ \\
\hline Subjective improvement in pain if MC was pain & & $62 \%(29 / 47)$ & $50 \%(18 / 36)$ \\
\hline
\end{tabular}

MIO: Maximum Interincisal Opening, Limited MIO: a Maximum Interincisal Opening of $\leq 35 \mathrm{~mm}$, MC: Main Complaint 

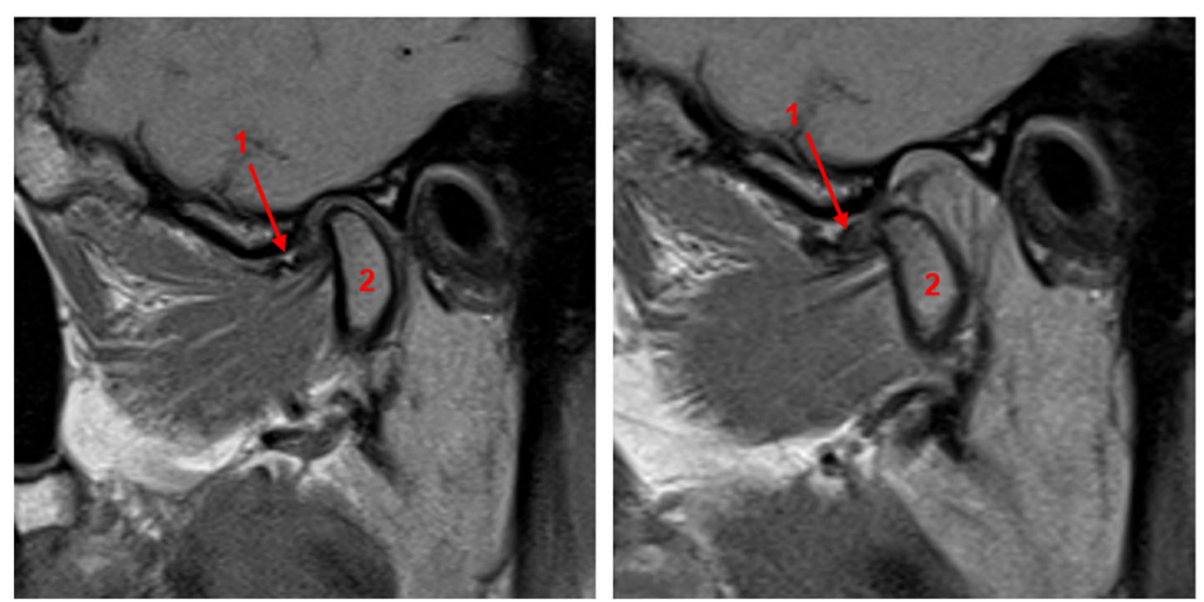

Fig. 1 Example of a patient with a crumpled disc [1] visualized on T1-weighted MRI. The left image was taken with a closed mouth, the right image with an open mouth. Also note the anterior disc displacement without reduction. The condyle [2] only showed minor degenerative changes

analysis for patients who designated limited mouth opening or joint sounds as their main complaint.

\section{Discussion}

With a subjective improvement of the main complaint in $62 \%$ of cases at short-term follow-up and 53\% at medium-term follow-up, our success rates are rather low if compared to previous studies [7, 9, 18, 19, 22]. Ulmner and colleagues found in their short-term prospective study that only $11 \%$ of patients with DJD, $20 \%$ with ADDwoR and $36 \%$ with chronic inflammatory arthritis showed no or little improvement after arthroscopy [19]. Haeffs et al. on the other hand only had a successful surgical outcome in $62.3 \%$ of patients with TMJ arthralgia or internal derangement [7]. Other reports describe successful outcomes in $67 \%$ of patients with arthralgia with or without OA, rheumatic disease or chronic closed lock, in $80 \%$ of patients with ADDwoR and $86,7 \%$ in patients with internal derangement $[9,18,22]$. MuñozGuerra et al. had a success rate of $54.24 \%$ in patients with internal derangement [11]. It is hard to have a direct comparison of all these results considering heterogeneity in disease classification, presentation, and followup. Although more recently, diagnostic criteria for temporomandibular disorders, known as the DC/TMD, are available they are not universally used in clinical practice $[23,24]$. Secondly, the duration of the symptoms before the arthroscopic intervention might play an important role in the success of arthroscopic lysis and lavage [9, 25]. The average time between the first consult and the arthroscopy was 18.9 months. Israel et al. found a negative correlation between duration of the symptoms and success of an arthroscopy in patients with inflammatory or degenerative TMJ diseases [25]. Thirdly, it is important to note that only 36 out of the 47 patients attended a MT appointment which leads to a possible incomplete representation of MT success rates.

Hyaluronic acid was injected during the arthroscopic procedure in four joints where there were signs of severe degenerative joint disease as it might have a positive effect on pain reduction [26]. However, a recent randomized controlled trial published in 2021 with 51 patients (Wilkes stage-III and stage-IV) observed no beneficial effect of hyaluronic acid on pain reduction compared to arthroscopy alone [27]. These new insights were not available at the time the arthroscopies were performed but are important to take into account when performing arthroscopies in the future. There were too few patients who received hyaluronic acid in this study to draw any conclusions of its effect on reducing pain.

In a previous study we showed the poor correlation between arthroscopic and MRI findings in patients with TMD. This means that when blinded to clinical information MRI and arthroscopic observations can lead to different conclusions. There was only a fair agreement reached for the reduction capacity of the disc and disc perforation [20]. In this study our main aim was to find identify different variables observed during MRI and/or arthroscopy that are significantly correlated with success of the arthroscopic lysis and lavage. On MRI, an irregular, crumpled or rounded disc is mostly seen in later stages of internal derangement. In the early stages, the disc retains its normal shape [28]. The fact that the absolute or probable absence of a crumpled disc and the absolute absence of a rounded disc deformation, i.e. absence of clear signs of advanced internal derangement, correlated with better outcomes suggests that early intervention in internal derangement might be beneficial 
Table 4 Stepwise regression model

\begin{tabular}{|c|c|c|c|}
\hline \multirow[b]{2}{*}{ MRI } & \multirow[b]{2}{*}{ ST improvement in MC in the entire population } & \multirow{2}{*}{$\begin{array}{l}\text { Variable } \\
\text { Crumpled disc } \leq 3\end{array}$} & \multirow{2}{*}{$\begin{array}{l}P \text {-Value } \\
0.0112\end{array}$} \\
\hline & & & \\
\hline & & Rounded disc $\leq 1$ & 0.073 \\
\hline & & Articular eminence deformation $\leq 1$ & 0.0848 \\
\hline & & Lateral pterygoid muscle anomaly $\leq 2$ & 0.1763 \\
\hline & & Joint effusion $\leq 2$ & 0.2095 \\
\hline & $\mathrm{ST}$ improvement in $\mathrm{MC}$ if $\mathrm{MC}$ is pain & Condylar Deformation $\leq 4$ & 0.0029 \\
\hline & & Lateral pterygoid muscle deformation $\leq 2$ & 0.0049 \\
\hline & & Articular eminence deformation $\leq 1$ & 0.0052 \\
\hline & & Rounded disc $\leq 1$ & 0.0227 \\
\hline & MT improvement in $\mathrm{MC}$ in the entire population & Crumpled disc $\leq 3$ & 0.0054 \\
\hline & & DJD & 0.1861 \\
\hline & & Inflammatory arthritis & 0.1992 \\
\hline & $\mathrm{MT}$ improvement in $\mathrm{MC}$ if $\mathrm{MC}$ is pain & Articular eminence deformation $\leq 1$ & 0.0325 \\
\hline \multirow[t]{7}{*}{ Arthroscopy } & ST improvement in $\mathrm{MC}$ in the entire population & DJD & 0.0178 \\
\hline & & Haemorrhagic infiltration of the medial synovium $\leq 1$ & 0.0845 \\
\hline & & Other & 0.068 \\
\hline & ST improvement in $M C$ if $M C$ is pain & Reduction $\leq 2$ & 0.0744 \\
\hline & & Other & 0.4226 \\
\hline & MT improvement in $\mathrm{MC}$ in the entire population & Displacement of the disc $\leq 4$ & 0.058 \\
\hline & MT improvement in $\mathrm{MC}$ if $\mathrm{MC}$ is pain & Articular eminence deformation $\leq 4$ & 0.2853 \\
\hline \multirow[t]{8}{*}{ MRI + Arthroscopy } & ST improvement in $\mathrm{MC}$ in the entire population & Reduction (arthroscopy) $\leq 2$ & 0.0474 \\
\hline & & Other (arthroscopy) & 0.3772 \\
\hline & ST improvement in $M C$ if $M C$ is Pain & DJD (arthroscopy) & 0.0559 \\
\hline & & Other (arthroscopy) & 0.1823 \\
\hline & & Joint effusion $(M R I) \leq 1$ & 0.1418 \\
\hline & $\mathrm{MT}$ improvement in $\mathrm{MC}$ in the entire population & Crumpled disc $(M R I) \leq 3$ & 0.0078 \\
\hline & & DJD (MRI) & 0.0581 \\
\hline & MT improvement in $M C$ if $M C$ is Pain & Articular eminence deformation (arthroscopy) $\leq 4$ & 0.9984 \\
\hline
\end{tabular}

MRI: Magnetic resonance imaging, ST: short-term, MT: medium-term, MC: Main Complaint, DJD: Degenerative Joint Disease. P-values in bold are significant. 5-point Likert scale (1. absolutely not present; 2 . probably not present; 3 . uncertain; 4 . probably present; 5 . absolutely present)

for patients; although care should be taken not to overtreat patients. Some authors also believe that increased thickness of the attachment of the lateral pterygoid muscle can be seen as an indirect sign of progression in TMJ dysfunction and that flattening of the articular eminence can be interpreted as a secondary result of internal derangement $[13,28,29]$. The absolute and probable absence of lateral pterygoid muscle deformations and absolute absence of articular eminence deformations correlated significantly with improvement in pain at the ST, again suggesting the positive effect of the lysis and lavage before signs of the advanced disease become visible on MRI. Other studies support these findings that arthroscopic interventions might be more beneficial in early stages of TMD [9, 25, 30]. For example, in a recent network meta-analysis comparing different treatments for arthrogenous TMDs, AlMoraissi et al. reported that minimally invasive procedures were more effective than conservative treatments for reducing pain and increasing $\mathrm{MIO}$ in patients with internal derangement [30]. .Generally, non-invasive treatment strategies should be tried for at least 3-6 months prior to more invasive treatment modalities [2].

By combining the variables scored on MRI and during diagnostic arthroscopy, we attempted to make a combined prediction model. The absolute or probable absence of discal reduction evaluated on arthroscopic video was the only new significant variable in predicting improvement in main complaint in the short-term follow-up. Absence of discal reduction is mostly seen in patients suffering from ADDwoR. Patients with ADDwoR also tend to respond well on arthroscopy in 
other studies with success rates of up to $80 \%$ [19]. Part of the aetiology of ADDwoR is the presence of adhesions in the upper joint compartment. These adhesions are removed during a lysis and lavage procedure which can explain the success of arthroscopy in ADDwoR [9, 19]. The presence of adhesions during arthroscopy in patients suffering from internal derangement is also linked with a favourable outcome [11].

Our study had some limitations. The retrospective design increased the risk of bias and inaccurate data when reviewing patient records for the extraction of clinical parameters. Furthermore, because all arthroscopic videos were reviewed retrospectively, not being able to manipulate the scope during the assessment made the interpretation of the videos more difficult. In addition, while a stepwise regression model is a valuable tool for approaching considerable numbers of potential variables, it also has some drawbacks. If for example two variables are correlated strongly and both have a good relationship with the outcome, only one of those two variables is included in the model. This has the consequence that included variables can represent a group of variables that correlate strongly between themselves. Besides, a model selection is only successful for those patients where all variables are measured. This explains why results of the combined analysis differ from the separate analyses. Finally, a study population of 50 joints poses a statistical challenge and care should be taken to transfer these results to the general population.

\section{Conclusion}

In conclusion, patients presenting with TMD, should receive conservative treatment including reduction of joint loading by education, occlusal splints, NSAIDs or other pharmacological strategies for at least 3 to 6 months. When no or almost no improvement is observed, an MRI scan can be performed to further evaluate the underlying cause of the symptoms. MRI might also have a great potential in the future in predicting which patients might benefit the most from arthroscopic lysis and lavage. Disc shape and in particular the absolute or probable absence of a crumpled disc might be used as a predictive variable in patients suffering from TMD. The absence of eminence deformation on MRI also predicted better outcome in the medium-term follow-up. Perioperative findings such as DJD or absolute or probable absence of disc reduction might predict initial improvement of the main complaint. Future studies are indicated to further evaluate what clinical or radiographic variables will improve selection criteria for patients undergoing an arthroscopy of the TMJ.

\section{Abbreviations}

ADDwoR: Anterior disc displacement without reduction; ADDwR: Anterior disc displacement with reduction; DJD: Degenerative joint disease;
IA: Inflammatory arthritis; MIO: Maximum interincisal opening; MRI: Magnetic resonance imaging; MT: Medium-term follow-up; ST: Short-term follow-up; TMD: Temporomandibular disorder; TMJ: Temporomandibular joint

\section{Acknowledgements}

Not applicable.

\section{Authors' contributions (CRediT roles)}

Kobbe Vervaeke: Conceptualization, Methodology, Investigation, Formal analysis, Writing - Original draft preparation. Pieter-Jan Verhelst:

Conceptualization, Methodology, Investigation, Formal analysis, Writing Original draft preparation. Kaan Orhan: Conceptualization, Methodology, Investigation, Writing - Review \& Editing. Bodil Lund: Conceptualization, Methodology, Investigation, Writing - Review \& Editing. Daniel Benchimol: Conceptualization, Methodology, Investigation, Writing - Review \& Editing. Fréderic Van der Cruyssen: Conceptualization, Methodology, Writing Review \& Editing. Antoon De Laat: Conceptualization, Methodology, Writing - Review \& Editing. Reinhilde Jacobs: Conceptualization, Methodology, Writing - Review \& Editing. Constantinus Politis: Conceptualization, Methodology, Writing - Review \& Editing. All authors read and approved the final manuscript.

\section{Funding}

This research did not receive any specific grant from funding agencies in the public, commercial, or not-for-profit sectors.

\section{Availability of data and materials}

The datasets used and/or analyzed during the current study are available from the corresponding author on reasonable request.

\section{Declarations}

Ethics approval and consent to participate

Ethical approval was given by the Research Ethics Committee UZ/KU Leuven (MP 012487).

\section{Consent for publication}

Not applicable.

\section{Competing interests}

The authors declare that they have no competing interests.

\section{Author details}

'Department of Oral and Maxillofacial Surgery, University Hospitals Leuven, Campus Sint-Rafaël, Kapucijnenvoer 33, BE-3000 Leuven, Belgium. ${ }^{2} \mathrm{OMFS}$ IMPATH Research Group, Department of Imaging and Pathology, Faculty of Medicine, KU Leuven, Leuven, Belgium. ${ }^{3}$ Department of Dentomaxillofacial Radiology, Faculty of Dentistry, Ankara University, Ankara, Turkey.

${ }^{4}$ Department of Clinical Dentistry, Faculty of Medicine, University of Bergen Bergen, Norway. ${ }^{5}$ Department of Oral and Maxillofacial Surgery, Haukeland University Hospital, Bergen, Norway. ${ }^{6}$ Department of Dental Medicine, Karolinska Institutet, Stockholm, Sweden. ${ }^{7}$ Department of Oral Health Sciences, KU Leuven, Leuven, Belgium. ${ }^{8}$ Department of Dentistry, University Hospitals, Leuven, Belgium.

Received: 17 September 2021 Accepted: 13 December 2021

Published online: 07 January 2022

\section{References}

1. Dym H, Israel H. Diagnosis and Treatment of Temporomandibular Disorders. Dent Clin N Am. 2012;56(1):149-61. https://doi.org/10.1016/j.cden.2011.08. 002.

2. Scrivani SJ, Keith DA, Kaban LB. Temporomandibular disorders. N Engl J Med. 2008;359(25):2693-705. https://doi.org/10.1056/NEJMra0802472.

3. Poveda Roda R, Bagan JV, Díaz Fernández JM, Hernández Bazán S, Jiménez SY. Review of temporomandibular joint pathology. Part I: classification, epidemiology and risk factors. Med Oral Patol Oral Cir Bucal. 2007;12(4): E292-8.

4. Sato FRL, Lima CAA, Tralli G, da Silva RA. Is there a correlation between arthroscopic findings and the clinical signs and symptoms of patients with internal derangement of the temporomandibular joint? A prospective study. 
Int J Oral Maxillofac Surg. 2019;48(2):233-8. https://doi.org/10.1016/j.ijom.201 8.07.004.

5. Ohnishi M. Arthroscopy of the temporomandibular joint. J Stomatol Soc. 1975;42(2):207-13. https://doi.org/10.5357/koubyou.42.207.

6. Sanders B. Arthroscopic surgery of the temporomandibular joint: treatment of internal derangement with persistent closed lock. Oral Surg Oral Med Oral Pathol. 1986;62(4):361-72. https://doi.org/10.1016/0030-4220(86)902 82-3.

7. Haeffs TH, D'Amato LN, Khawaja SN, Keith DA, Scrivani SJ. What variables are associated with the outcome of arthroscopic lysis and lavage surgery for internal derangement of the temporomandibular joint? J Oral Maxillofac Surg. 2018;76(10):2081-8. https://doi.org/10.1016/j.joms.2018.04.018.

8. González-García R, Gil-Díez Usandizaga JL, Rodríguez-Campo FJ. Arthroscopic anatomy and lysis and lavage of the temporomandibular joint. Atlas Oral Maxillofac Surg Clin N Am. 2011;19(2):131-44. https://doi.org/10.1 016/j.cxom.2011.05.002

9. Machoň V, Šedý J, Klíma K, Hirjak D, Foltán R. Arthroscopic lysis and lavage in patients with temporomandibular anterior disc displacement without reduction. Int J Oral Maxillofac Surg. 2012;41(1):109-13. https://doi.org/10.1 016/j.ijom.2011.07.907.

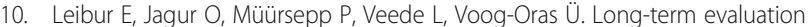
of arthroscopic surgery with lysis and lavage of temporomandibular joint disorders. J Cranio-Maxillofac Surg. 2010;38(8):615-20. https://doi.org/10.101 6/j.jcms.2010.02.003.

11. Muñoz-Guerra MF, Rodríguez-Campo FJ, Escorial-Hernández V, Brabyn PJ, Fernández-Domínguez M, Naval-Gías L. Is there a relationship between age, personal factors or surgical findings, and outcome after temporomandibular joint arthroscopy? J Oral Maxillofac Surg. 2021;79(5):1000-8. https://doi.org/1 0.1016/j.joms.2020.12.016.

12. Murakami Kl, Segami N, Okamoto M, Yamamura I, Takahashi K, Tsuboi Y. Outcome of arthroscopic surgery for internal derangement of the temporomandibular joint: long-term results covering 10 years. J CranioMaxillofac Surg. 2000;28(5):264-71. https://doi.org/10.1054/jcms.2000.0162.

13. Talmaceanu D, Lenghel LM, Bolog N, Hedesiu M, Buduru S, Rotar H, et al. Imaging modalities for temporomandibular joint disorders: an update. Clujul Med. 2018;91(3):280-7. https://doi.org/10.15386/cjmed-970.

14. De Laat A, Horvath M, Bossuyt M, Fossion E, Baert AL. Myogenous or arthrogenous limitation of mouth opening: correlations between clinical findings, MRI, and clinical outcome. J Orofac Pain. 1993;7(2):150-5.

15. Vogl TJ, Lauer H-C, Lehnert T, Naguib NNN, Ottl P, Filmann N, et al. The value of MRI in patients with temporomandibular joint dysfunction: correlation of MRI and clinical findings. Eur J Radiol. 2016;85(4):714-9. https://doi.org/10.1016/j.ejrad.2016.02.001.

16. Zhang $S$, Yang $C$, Chen M, Fan $X$, Yun B, Peng $Y$, et al. Magnetic resonance imaging in the diagnosis of intra-articular adhesions of the temporomandibular joint. Br J Oral Maxillofac Surg. 2009;47(5):389-92. https://doi.org/10.1016/j.bjoms.2008.09.007.

17. Thomas N, Harper DE, Aronovich S. Do signs of an effusion of the temporomandibular joint on magnetic resonance imaging correlate with signs and symptoms of temporomandibular joint disease? Br J Oral Maxillofac Surg. 2018;56(2):96-100. https://doi.org/10.1016/j.bjoms.2017.11. 011.

18. Ulmner M, Kruger-Weiner C, Lund B. Patient-Specific Factors Predicting Outcome of Temporomandibular Joint Arthroscopy: A 6-Year Retrospective Study. J Oral Maxillofac Surg. 2017;75(8):1643.e1-7.

19. Ulmner $M$, Weiner CK, Lund B. Predictive factors in temporomandibular joint arthroscopy: a prospective cohort short-term outcome study. Int J Oral Maxillofac Surg. 2020;49(5):614-620. https://doi.org/10.1016/j.ijom.2019.09. 002.

20. Verhelst PJ, Vervaeke K, Orhan K, Lund B, Benchimol D, Coucke W, et al. The agreement between magnetic resonance imaging and arthroscopic findings in temporomandibular joint disorders. Int J Oral Maxillofac Surg. 2020;50(5):657-64. https://doi.org/10.1016/j.ijom.2020.10.012.

21. McCain JP, de la Rua H, LeBlanc WG. Puncture technique and portals of entry for diagnostic and operative arthroscopy of the temporomandibular joint. Arthrosc J Arthrosc Relat Surg. 1991;7(2):221-32. https://doi.org/10.101 6/0749-8063(91)90111-A.

22. Smolka W, lizuka T. Arthroscopic lysis and lavage in different stages of internal derangement of the temporomandibular joint: correlation of preoperative staging to arthroscopic findings and treatment outcome. J
Oral Maxillofac Surg. 2005;63(4):471-8. https://doi.org/10.1016/j.joms.2004.07. 021.

23. Schiffman E, Ohrbach R, Truelove E, Look J, Anderson G, Goulet J-P, et al. Diagnostic criteria for temporomandibular disorders (DC/TMD) for clinical and research applications: recommendations of the international RDC/TMD consortium network* and orofacial pain special interest groupt. J Oral Facial Pain Headache. 2014;28(1):6-27. https://doi.org/10.11607/jop.1151.

24. Lund B, Ulmner M, Bjørnland T, Berge T, Olsen-Bergem H, Rosèn A. A disease-focused view on the temporomandibular joint using a delphiguided process. J Oral Sci Nihon University, School of Dentistry. 2020;62:1-8.

25. Israel HA, Behrman DA, Friedman JM, Silberstein J. Rationale for early versus late intervention with arthroscopy for treatment of inflammatory/ degenerative temporomandibular joint disorders. J Oral Maxillofac Surg. 2010;68(11):2661-7. https://doi.org/10.1016/j.joms.2010.05.051.

26. Morey-Mas MA, Caubet-Biayna J, Varela-Sende L, Iriarte-Ortabe JI. Sodium hyaluronate improves outcomes after arthroscopic lysis and lavage in patients with Wilkes stage III and IV disease. J Oral Maxillofac Surg. 2010; 68(5):1069-74. https://doi.org/10.1016/j.joms.2009.09.039.

27. Castaño-Joaqui OG, Cano-Sánchez J, Campo-Trapero J, Muñoz-Guerra MF. TMJ arthroscopy with hyaluronic acid: a 12-month randomized clinical trial. Oral Dis. 2021;27(2):301-11. https://doi.org/10.1111/odi.13524.

28. Tomas X, Pomes J, Berenguer J, Quinto L, Nicolau C, Mercader JM, et al. MR imaging of temporomandibular joint dysfunction: a pictorial review. Radiographics. 2006;26(3):765-81. https://doi.org/10.1148/rg.263055091.

29. Hirata FH, Guimarães AS, de Oliveira JX, Moreira CR, Ferreira ETT, Cavalcanti MGP. Evaluation of TMJ articular eminence morphology and disc patterns in patients with disc displacement in MRI. Braz Oral Res. 2007;21(3):265-71. https://doi.org/10.1590/S1806-83242007000300013.

30. Al-Moraissi EA, Wolford LM, Ellis E, Neff A. The hierarchy of different treatments for arthrogenous temporomandibular disorders: a network meta-analysis of randomized clinical trials. J Cranio-Maxillofac Surg. 2020; 48(1):9-23. https://doi.org/10.1016/j.jcms.2019.10.004

\section{Publisher's Note}

Springer Nature remains neutral with regard to jurisdictional claims in published maps and institutional affiliations.

Ready to submit your research? Choose BMC and benefit from:

- fast, convenient online submission

- thorough peer review by experienced researchers in your field

- rapid publication on acceptance

- support for research data, including large and complex data types

- gold Open Access which fosters wider collaboration and increased citations

- maximum visibility for your research: over $100 \mathrm{M}$ website views per year

At BMC, research is always in progress.

Learn more biomedcentral.com/submissions 